Revista Universo Contábil, ISSN 1809-3337

FURB, v. 5, n.3, p. 82-98, jul./set., 2009

doi:10.4270/ruc.2009323

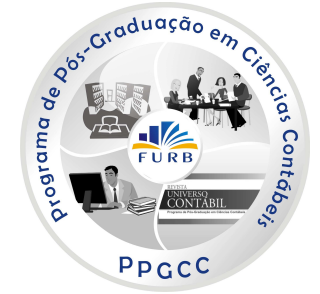

\title{
IMPACTOS DA GOVERNANÇA CORPORATIVA E DA ESTRUTURA DE CONTROLE NA CONSOLIDAÇÃO DE DEMONSTRAÇÕES FINANCEIRAS EM COMBINAÇÕES DE NEGÓCIOS: O ESTUDO DE CASO DA COPEL 1
}

\section{IMPACTS OF CORPORATE GOVERNANCE AND CONTROL STRUCTURE ON THE CONSOLIDATION OF FINANCIAL STATEMENTS IN BUSINESS COMBINATIONS: THE CASE STUDY OF COPEL}

Ricardo Vinícius Dias Jordão

Mestrando em Ciências Contábeis na UFMG Endereço: Avenida Antônio Carlos, nº 6627 - Bairro Pampulha CEP: 31270-901 - Belo Horizonte/MG - Brasil

E-mail: jordaoconsultor@yahoo.com.br Telefone: (31) 3409-7057

\section{Antônio Artur de Souza}

PHD in Management Sciences Professor do Mestrado em Ciências Contábeis da UFMG Endereço: Avenida Antônio Carlos, nº 6627 - Bairro Pampulha CEP: 31270-901 - Belo Horizonte/MG - Brasil E-mail : artur@face.ufmg.br Telefone: (31) 3409-7057

Débora Lage Lélis

Mestranda em Ciências Contábeis na UFMG Endereço: Avenida Antônio Carlos, nº 6627 - Bairro Pampulha CEP: 31270-901 - Belo Horizonte/MG - Brasil E-mail : deboralml@yahoo.com.br Telefone: (31) 3409-7057

Régis Monteiro Ferreira

Mestrando em Ciências Contábeis na UFMG Endereço: Avenida Antônio Carlos, nº 6627 - Bairro Pampulha CEP: 31270-901 - Belo Horizonte/MG - Brasil E-mail: regis@valuenegocios.com.br

Telefone: (31) 3409-7057

\footnotetext{
Artigo recebido em 10.10.2008. Revisado por pares em 18.12.2008. Reformulado em 10.03.2009. Recomendado em 18.03.2009 por Ilse Maria Beuren (Editora). Publicado em 30.09.2009. Organização responsável pelo periódico: FURB.
} 


\section{RESUMO}

Este artigo apresenta os resultados de uma pesquisa que teve como objetivo geral analisar as diferenças entre as normas brasileiras e norte-americanas no que tange à consolidação de participações em investimentos. Ela teve quatro objetivos específicos: (1) discutir a importância do processo de consolidação das demonstrações financeiras para os usuários de informações; (2) analisar os princípios e os regulamentos que orientam esse processo no Brasil e nos Estados Unidos da América (EUA), frente à estrutura de controle corporativa; (3) identificar as similaridades e divergências existentes entre as normas desses dois países em relação à divulgação financeira em casos de combinações de negócios $(\mathrm{CN})$; e (4) determinar a relevância dessas iniciativas para redução dessas possíveis divergências com vistas a obter melhorias nas práticas de GC e para a redução da assimetria informacional do usuário externo. $\mathrm{O}$ artigo inicia-se com uma revisão da literatura brasileira e norte-americana sobre o tema. Além da pesquisa bibliográfica e documental, a pesquisa também compreendeu uma avaliação da necessidade de harmonização das práticas contábeis nas CN da COPEL. Nesse sentido, o artigo apresenta uma discussão sobre os possíveis impactos das divergências informacionais para os investidores, sobre as $\mathrm{CN}$ da empresa estudada. Pôde-se concluir (1) que há significativas divergências nas informações consolidadas, em função das diferentes normas e práticas contábeis do Brasil e dos EUA, para grupos com investimentos em CN; (2) que o desconhecimento dessas diferenças pode prejudicar a análise financeira $\mathrm{e}$, conseqüentemente, as decisões de investimento dos investidores.

Palavras-chave: Governança corporativa. Consolidação em combinações de negócios. Estrutura de propriedade e controle.

\section{ABSTRACT}

This paper presents the results of a research that aimed at analyzing the differences between the Brazilian and the American practices on the consolidation of investments. The research had four specific objectives: 1) to discuss the importance of information from consolidated financial statements (FS); (2) to analyze the principles and policies guiding this process in both Brazil and USA; (3) to identify similarities and discrepancies between the sets of standards of this two countries, specifically in terms of FS consolidation for business combinations $(B C)$; and (4) to determine the relevance of these initiatives to reduce possible divergences aiming at both improving the $C G$ practices and reducing information asymmetry. Firstly, the paper presents a review of Brazilian and North American literature on the subject. Besides the bibliographical and documentary research, this study also involved the assessment of the need for conciliating accounting practices in the case of COPEL. Concerning to it, the article presents a discussion on the possible impacts of the informational divergences on the investors, referring to the BCs of the studied company. It was concluded that: (1) there are significant divergences in the consolidated information, due to the different accounting standards in Brazil and in the USA to the groups with BC investments; (2) the non-acknowdgement of these differences and divergences can hinder the financial analysis and, consequently, the investors' decisions of investments.

Keywords: Corporate governance; consolidation in business combinations; property and control structure 


\section{INTRODUÇÃO}

A governança corporativa (GC) é um tema que tem tido notável destaque tanto no meio acadêmico quanto no meio empresarial (AMARAL et al., 2008). Seu surgimento ocorreu para reduzir ao máximo o conflito de agência entre os proprietários e gerentes, decorrente da separação da propriedade da gestão (MARTINS; SILVA; NARDI, 2006). Ela refere-se às práticas que cuidam de otimizar o desempenho de uma companhia ao proteger todas as partes interessadas e facilitar o acesso às fontes de capital (CVM, 2002). As boas práticas de GC têm a finalidade de aumentar o valor da sociedade, de contribuir para sua perenidade e de assegurar que os gestores se comportem de acordo com as expectativas dos proprietários (IBGC, 2008). Nesse sentido, observa-se que a relevância da discussão sobre os meios de verificar a veracidade das informações prestadas pelas empresas à sociedade e sobre os mecanismos de controle que assegurem a qualidade das mesmas e sua transparência tem se tornado cada vez maior (JORDÃO; SOUZA, 2008). De um modo especial, percebe-se que as empresas e órgãos normatizadores estão buscando meios de promover uma maior evidenciação das informações disponibilizadas pelas empresas à sociedade e de melhorar a qualidade das práticas de GC.

A transparência é um dos determinantes da GC que, dentre outras coisas, preza por um nível adequado de evidenciação contábil (LANZANA; SILVEIRA; FAMÁ, 2006). Assim, verifica-se, atualmente, um aumento na necessidade de harmonização e de maior clareza na divulgação das informações financeiras além das fronteiras como medidas a serem implementadas para salvaguardar o interesse dos investidores (JORDÃO; SOUZA, 2008), pois eles são atraídos para mercados que conhecem e nos quais confiam. A harmonização traz desafios para os estudiosos, profissionais e usuários da contabilidade, bem como para as entidades responsáveis pela emissão de normas contábeis, que passam a desempenhar um importante papel nesse processo. Uma das questões primordiais que carecem de tratamento harmônico é a consolidação das demonstrações financeiras (DF), tendo em vista o crescente aumento do volume de combinações de negócios $(\mathrm{CN})$, que se processam em todo mundo (SANTOS; SCHMIDT; FERNANDES, 2003).

As operações de CN são uma opção estratégica de crescimento das empresas, capaz de reduzir custos e proporcionar grandes retornos financeiros aos investidores. Atualmente, essas operações se orientam, principalmente, pela concentração das empresas em torno de seu core business (negócio central). Seu volume tem se intensificado em função da pressão por redução de custos e riscos, do desejo por maior flexibilidade e, ainda, da busca por vantagens competitivas sustentáveis (JORDÃO; SOUZA, 2008). Entretanto, quando são realizadas no exterior ou em empresas que precisem reportar seus dados para outros mercados abre-se espaço para o oportunismo, gerando custos adicionais de monitoramento e provocando a necessidade da divulgação de informações adicionais sobre tais operações.

A divulgação financeira deveria fornecer informação útil à tomada de decisões racionais de investimento para os usuários dessas informações (SFAC 1). O monitoramento dos investimentos realizados pode ser prejudicado pelas diferenças das normas relacionadas ao registro dos fatos contábeis e das formas de evidenciação financeira entre os países. Epstein, Nach e Bragg (2005) explicam que essas diferenças são provocadas porque as normas contábeis são uma reação e um produto do ambiente econômico em que elas se desenvolvem.

As fronteiras entre as nações, contudo, não constituem barreiras para os investidores. Hoje, eles podem investir em mercados de diferentes países e continentes, em empresas domésticas, multinacionais ou transnacionais. As DF dessas empresas constituem importante fonte de informação para a tomada de decisão do investidor, para quem a comparabilidade dos relatórios financeiros é fundamental para subsidiar suas escolhas e monitorar seus investimentos. Young e Guenther (2003) postulam que o custo para o investidor tornar-se 
bem informado é uma barreira potencial ao movimento de capitais. Dessa forma, o conhecimento das divergências informacionais é desejável por facilitar as análises dos investidores e diminuir o risco de decisões tomadas.

As boas práticas de GC deveriam colaborar para a redução das divergências informacionais que possam existir entre os países, visando salvaguardar o interesse dos investidores estrangeiros, estimular uma maior fluidez no fluxo de capitais internacionais e que as práticas contábeis dos países sejam mais harmônicas. Jensen e Meckling (1976), baseando-se na Teoria de Finanças, observaram que as relações de propriedade e controle são afetadas pelo comportamento gerencial e que os proprietários precisam incorrer em custos de agência para reduzir o oportunismo dos gestores. Dizem que a assimetria informacional pode provocar oportunismo e afetar o interesse dos investidores pelas decisões dos gestores das empresas que, muitas vezes, promovem seu próprio interesse em detrimento dos acionistas. Essa situação caracteriza-se como um conflito de agência entre os acionistas (principais) e os gestores (agentes), que pode ser minimizada por um monitoramento e controle adequado das decisões destes, por aqueles. Baseando-se nessa premissa, Amaral et al. (2008) postulam que a assimetria informacional existente entre gestores e acionistas, numa empresa de capital aberto, é considerada geradora de um indesejado aumento do custo de capital, decorrente da exigência de maiores retornos pelos investidores. Explicam que um maior nível de evidenciação haveria de minimizar tal assimetria e, assim, reduzir os custos de capital correlatos e melhorar o nível de GC.

A questão da propriedade e do controle é central na análise das $\mathrm{CN}$, por indicar a legitimidade do exercício do poder, por determinar os rumos a serem seguidos pelas corporações e por afetar o processo de consolidação das DF. Stickney e Weil (2001) afirmam que as DF consolidadas geralmente fornecem informações mais úteis aos acionistas da controladora, do que as demonstrações das empresas separadas. Devido à sua participação votante, a holding pode efetivamente controlar o uso dos ativos da subsidiária fazendo com que, na maioria dos casos, o investidor também tenha maior interesse nos reportes do grupo. Nos Estados Unidos da América (EUA), por exemplo, ao contrário do Brasil, as DF individuais da controladora não são divulgadas, apenas as demonstrações consolidadas são publicadas. Essas e outras diferenças podem gerar a necessidade de ajustes para evidenciação das informações pelas empresas que tem ações negociadas nas bolsas de valores desses dois mercados.

A pergunta que sintetiza o problema de pesquisa é: Quais as diferenças entre as normas brasileiras e norte-americanas no que tange à consolidação de participações em investimentos e como elas podem influenciar as decisões de investimento dos investidores? $\mathrm{O}$ objetivo deste estudo é analisar as diferenças entre as normas brasileiras e norte-americanas no que tange à consolidação de participações em investimentos. Adicionalmente, a pesquisa irá: (1) discutir a importância do processo de consolidação das demonstrações financeiras para os usuários de informações; (2) analisar os princípios e os regulamentos que orientam esse processo no Brasil e nos Estados Unidos da América (EUA), frente à estrutura de controle corporativa; (3) identificar as similaridades e divergências existentes entre as normas desses dois países em relação à divulgação financeira em casos de combinações de negócios $(\mathrm{CN})$; e (4) determinar a relevância dessas iniciativas para redução dessas possíveis divergências com vistas a obter melhorias nas práticas de GC e para a redução da assimetria informacional do usuário externo.

A justificativa deste estudo fundamenta-se na necessidade de melhorar a informação para tomada de decisões dos investidores e na busca pela compreensão das divergências informacionais que carecem de tratamento harmônico pela contabilidade. Ele fundamenta-se também na Teoria de Finanças que preconiza que a melhoria nos níveis de GC e de evidenciação financeira colabora para a redução dos custos de monitoramento e para a 
redução de atitudes oportunísticas. Finalmente, observa-se que a indicação desta pesquisa consta nas recomendações de Jordão e Souza (2008), que indicaram uma lacuna de pesquisa nessa área, e de Futura e Santos (2006), que observaram a existência de poucos trabalhos sobre o tema.

Este artigo está dividido em cinco seções, contando com esta introdução. Na próxima seção descreve-se a metodologia da pesquisa. Na seção 3, analisa-se a consolidação das demonstrações financeiras em combinações de negócios no Brasil e nos EUA. Na seção 4, apresenta-se o estudo de caso da Companhia Paranaense de Energia Elétrica (COPEL), a partir da proposta construída ao longo do referencial teórico, descrevendo as inovações, os ajustes e os resultados encontrados. Por fim, na seção 5, as conclusões são apresentadas de acordo com os objetivos pretendidos.

\section{METODOLOGIA}

Neste estudo primeiramente discutem-se as regras de consolidação do Brasil e EUA e suas divergências na consolidação das DF, a partir da análise dos balanços patrimoniais consolidados da COPEL. As DF consolidadas são utilizadas para facilitar a comparabilidade entre as informações divulgadas nesses dois países. A comparação foi feita para identificar quais ajustes foram necessários para divulgação das informações consolidadas do Brasil nos EUA segundo o conjunto de normas contábeis existentes nos dois países, referidas neste artigo como BR GAAP e US GAAP. Tendo em vista o universo de diferenças possíveis de serem avaliadas o foco da análise voltou-se para as $\mathrm{CN}$ dessa companhia. As diferenças foram observadas nas participações em controladas e coligadas divulgadas nos DF de 2006. Este exercício referia-se ao último exercício disponível para análise na data da comparação (princípio de 2008) considerando que as DF divulgadas no Brasil ao final de um exercício fiscal são convertidas para USGAAP e divulgadas até meados do ano seguinte. A escolha da empresa foi intencional por se tratar de um grupo expressivo no setor elétrico que realizou várias operações de $\mathrm{CN}$ nos últimos anos.

A COPEL é uma sociedade de economia mista, controlada pelo Governo do Estado do Paraná, que abriu seu capital ao mercado de ações em abril de 1994 (BOVESPA, 2008) e tornou-se, em julho de 1997, a primeira companhia do setor elétrico brasileiro listada na Bolsa de Valores de Nova York e, desde junho de 2002, na Latibex - o braço latino-americano da Bolsa de Valores de Madri (COPEL, 2008c). A COPEL foi criada através do Decreto ${ }^{\circ}$ 14.947 de 26 de outubro de 1954. A partir de 1956, ela passou a centralizar todas as ações governamentais de planejamento, construção e exploração dos sistemas de produção, transmissão, transformação, distribuição e comércio de energia elétrica e serviços correlatos, tendo incorporado bens, serviços e obras em poder de diversos órgãos do Estado do Paraná.

Esta pesquisa classifica-se como exploratória por buscar estabelecer uma referência inicial sobre o assunto em questão e formar uma base para outras pesquisas (CASTRO, 2002). A metodologia é qualitativa, por não se basear em instrumentos estatísticos para a análise do problema (RICHARDSON, 1999). As principais fontes de consulta foram as DF consolidadas, registradas junto à Comissão de Valores Mobiliários (CVM), disponíveis na seção de Investidores da empresa (COPEL, 2008a,b) e no site da BOVESPA (www.bovespa.com.br), para análise em BR GAAP. Já as DF em US GAAP foram consultadas no relatório do Formulário 20-F, registrado junto à Securities and Exchange Comission (SEC), disponível no site (www.nyse.com). O 20-F é elaborado em inglês e seu prazo de arquivamento é de 180 dias após o encerramento do exercício fiscal, o que para as empresas brasileiras normalmente expira em 30 de junho. Nesse relatório divulgam-se, além das DF, informações sobre a empresa, gestores, conselheiros, honorários e serviços prestados pelos auditores externos, código de ética e sistemas de controle interno adotados. 


\section{ESTRUTURA DE CONTROLE E CONSOLIDAÇÃO DAS DEMONSTRAÇÕES FINANCEIRAS EM COMBINAÇÕES DE NEGÓCIOS NO BRASIL E EUA}

El Hajj e Lisboa (2001) entendem que uma CN é uma transação econômica em que uma sociedade obtém o controle sobre outra, ou quando duas empresas sob controles diferentes se associam para formar uma terceira, independentemente da forma legal como o controle é obtido e da forma resultante das empresas remanescentes. Segundo Jordão e Souza (2008) elas correspondem à união de empresas distintas em uma única entidade econômica por meio de concentrações ou reestruturações societárias, que requerem consolidação para evidenciar a posição econômica e patrimonial do grupo. As DF consolidadas são uma fonte de informação geralmente mais importante que os dados isolados de cada empresa, para o investidor e demais usuários externos.

A finalidade da consolidação é apresentar, prioritariamente, aos acionistas e credores da matriz, os resultados das operações e a posição financeira da holding e de suas subsidiárias essencialmente como se o grupo fosse uma única empresa com uma ou mais filiais (SHORTRIDGE; SMITH, 2007; ARB 51). No processo de consolidação devem ser excluídos: as participações de uma sociedade em outra, os saldos de quaisquer contas entre as entidades e os resultados não realizados entre essas sociedades (art. 250 da Lei ${ }^{\circ}$. 6404/76). Observa-se que a demonstração consolidada não é obtida pela simples soma dos saldos das empresas envolvidas, mas pela apresentação conjunta, com ajustes, das várias demonstrações.

No Brasil, a consolidação das DF é regulada pela Lei $\mathrm{n}^{\circ}$. 6.404 de 1976, alterada pelas Leis $\mathrm{n}^{\circ}$. 9.457 de 1997 e 10.303 de 2001 e revisada pela Lei $\mathrm{n}^{\circ} .11 .638$ de 2007. Adicionalmente, deve seguir a Instrução CVM nº. 247, de 1996, e suas alterações posteriores. A Lei $n^{\circ} .11 .638$, de 2007, não alterou os critérios para consolidação das demonstrações financeiras no Brasil. Nos EUA, o ARB 51, de 1959, e o SFAS 94 (Statement of Financial Accounting Standards), de 1987, regulam o assunto. Já para as demonstrações de períodos iniciados após 15 de dezembro de 2008, deverão ser observados também o SFAS 141 e o SFAS 160. Além delas, a EITF 96.16 (Emerging Issues Task Force) dicute questões relativas à consolidação de participações majoritárias quando os minoritários possuem direito de veto ou aprovação. Lemes, Carvalho e Oliveira-Lopes (2007) acreditam que existe considerável sustentação para o argumento de que as normas contábeis internacionais, as IFRS e as norteamericanas, os US GAAP estão se tornando mais próximas ao longo dos anos.

Os Quadros 1 e 2 apresentam as principais regras relativas à consolidação de DF no Brasil e nos EUA. O Quadro 1 apresenta as principais diferenças do BR GAAP e US GAAP.

\begin{tabular}{|l|l|l|}
\hline \multicolumn{1}{|c|}{ Item } & \multicolumn{1}{|c|}{ BR GAAP } & \multicolumn{1}{c|}{ US GAAP } \\
\hline $\begin{array}{l}\text { Definição } \\
\text { subsidiária }\end{array}$ & $\begin{array}{l}\text { É feita com base no controle do capital } \\
\text { votante ou no poder de determinar } \\
\text { políticas operacionais e financeiras da } \\
\text { empresa. }\end{array}$ & $\begin{array}{l}\text { Participação majoritária no capital votante. } \\
\text { Entidades nas quis não tenha controle do } \\
\text { capital, mas tenha participação variável } \\
\text { devem ser consolidadas. }\end{array}$ \\
\hline $\begin{array}{l}\text { Sociedades de } \\
\begin{array}{l}\text { Propósitos } \\
\text { Específicos (SPEs) }\end{array}\end{array}$ & $\begin{array}{l}\text { Consolidadas quando a relação indicar } \\
\text { controle. }\end{array}$ & $\begin{array}{l}\text { Consolidadas se as exigências de } \\
\text { consolidação para a participação variável } \\
\text { for atendiada. }\end{array}$ \\
\hline $\begin{array}{l}\text { Não consolidação } \\
\text { de subsidiárias }\end{array}$ & $\begin{array}{l}\text { Consolidação requerida somente para } \\
\text { companhias abertas, podendo ser } \\
\text { excluídas subsidiárias com graves } \\
\text { problemas de continuidade e com } \\
\text { evidência de venda em futuro próximo, } \\
\text { formalizada. }\end{array}$ & $\begin{array}{l}\text { Somente se a empresa detentora do capital } \\
\text { votante não tiver controle da investida. }\end{array}$ \\
\hline $\begin{array}{l}\text { Apresentação de } \\
\text { Joint-Ventures }\end{array}$ & $\begin{array}{l}\text { Requerem consolidação proporcional. } \\
\text { Consolidação proporcional não é admitida, } \\
\text { método } \\
\text { de }\end{array}$ \\
\hline
\end{tabular}

Quadro 1 - Divergências nos critérios de consolidação em BR GAAP e US GAAP

Fonte: elaborado pelos autores. 
A CVM acolheu e aprovou o Pronunciamento do IBRACON NPC n .27 sobre apresentação e divulgação das DF. A Deliberação $n^{\circ}$. 448 de 2005 da CVM determina que tais demonstrações devem estar em sintonia com os padrões internacionais em função da necessidade do aumento de transparência e da segurança nas informações contábeis e por possibilitar, a um custo mais baixo, o acesso das empresas nacionais às fontes de financiamento externas. A alteração da forma de avaliação de coligadas contido no art. 248 da Lei $\mathrm{n}^{\mathrm{o}}$. 6.404/76 pela Lei $\mathrm{n}^{\circ}$. 11.638/07 veio contribuir neste sentido. Esta Lei alterou o parâmetro para avaliação de coligadas pelo método da equivalência patrimonial (MEP), sendo estabelecido que esse método seja aplicado a todas as coligadas em que a investidora tenha influência significativa - caracterizada quando a participação for de $20 \%$ ou mais do capital votante - ao contrário do disposto naquela, que estabeleceu como parâmetro o capital total.

\begin{tabular}{|c|c|c|c|c|}
\hline $\begin{array}{c}\text { Participação } \\
\text { Societária no } \\
\text { Capital Votante }\end{array}$ & $\begin{array}{c}\text { Nível de } \\
\text { Influência } \\
\text { Econômica }\end{array}$ & $\begin{array}{c}\text { Tipo de } \\
\text { Investimento }\end{array}$ & $\begin{array}{l}\text { Método de } \\
\text { Avaliação }\end{array}$ & $\begin{array}{c}\text { Apresentação no } \\
\text { Balanço } \\
\text { Patrimonial }\end{array}$ \\
\hline $0 \%-10 \% *$ & $\begin{array}{c}\text { Nenhuma ou } \\
\text { Pequena Influência }\end{array}$ & $\begin{array}{c}\text { Temporário de Curto } \\
\text { ou } \\
\text { Longo Prazo }\end{array}$ & $\begin{array}{l}\text { Custo ou Valor de } \\
\text { Mercado (o menor) }\end{array}$ & $\begin{array}{c}\text { Investimentos de CP } \\
\text { ou LP }\end{array}$ \\
\hline $10 \%|-| 50 \%$ & $\begin{array}{c}\text { Influência } \\
\text { Significativa }\end{array}$ & Coligada & MEP & $\begin{array}{l}\text { Investimentos } \\
\text { Permanentes }\end{array}$ \\
\hline Inferior a $50 \%$ & $\begin{array}{c}\text { Controle em } \\
\text { conjunto }\end{array}$ & Controlada & $\begin{array}{l}\text { Consolidação } \\
\text { proporcional }\end{array}$ & $\begin{array}{c}\text { Demonstrações } \\
\text { Consolidadas }\end{array}$ \\
\hline $\begin{array}{l}50 \%-\mid 100 \% * \\
* \text { capital social }\end{array}$ & Controle & Controlada & Consolidação & $\begin{array}{c}\text { Demonstrações } \\
\text { Consolidadas }\end{array}$ \\
\hline
\end{tabular}

Quadro 2 - Investimentos em Participações Societárias com Direito a Voto - BR GAAP Fonte: elaborado pelos autores.

As sociedades podem ser consideradas coligadas quando uma participa com mais de $10 \%$ do capital da outra sem controlá-la, caso em que seriam denominadas controladas (SANTOS, SCHMIDT; FERNANDES, 2003). Segundo o $\S 2^{\circ}$ do art. 248 da Lei $n^{\circ} .6 .404$ de 1976 , considera-se controlada a sociedade na qual a controladora é titular de direitos que lhe assegurem, de modo permanente, preponderância nas deliberações sociais e o poder de eleger a maioria dos administradores. A Lei $\mathrm{n}^{\circ}$. 6404/76 em seus artigos 251, 252 e 253 define como subsidiárias as companhias controlados por outras que também nomeiam sua administração. As subsidiárias integrais, por sua vez, são constituídas por uma só pessoa, assim com as firmas individuais. Estas são compostas por uma pessoa física e aquelas por uma só pessoa jurídica. Sociedade aqui entendida como um acordo consensual, em que duas ou mais pessoas se obrigam a conjugar esforços ou recursos, visando a consecução de um fim comum e 'pessoa', no seu conceito jurídico, entendida como todo ente capaz de assumir direitos e obrigações.

Em síntese, observa-se que no Brasil, pela análise das BR GAAP, as sociedades controladas deveriam ser avaliadas pelo MEP sempre que o investimento for relevante maior que $15 \%$ do PL da investidora - (SANTOS; SCHMIDT; FERNANDES, 2003). Já as coligadas deveriam ser avaliadas pelo MEP sempre que a investidora tiver influência significativa nos termos da Lei $\mathrm{n}^{\mathbf{o}}$. 11.638/07. Da análise, percebeu-se que as normas brasileiras, assim como as internacionais, permitem a consolidação proporcional das DF das subsidiárias controladas em conjunto, aplicando-se a parcela referente à participação societária proporcional da controladora na empresa controlada.

Já nos EUA, o AICPA, através do ARB 51 havia definido a regra geral de sua política de consolidação: a propriedade, por uma companhia, da maioria do capital votante de outra. Regra que prevalece até hoje (AICPA, 2008). Dessa forma, as US GAAP não permitem a 
consolidação proporcional das demonstrações de empresas sobre as quais haja controle compartilhado. Nesses casos, o tratamento seria o mesmo dado no Brasil às coligadas. $\mathrm{O}$ FASB, através do SFAS 94, determinou que as subsidiárias sobre as quais a controladora detém controle temporário não sejam consolidadas, bem como aquelas cujo controle não mais pertence à holding, em razão, por exemplo, de falência ou reorganização corporativa. Nas demonstrações em US GAAP, antes dos SFASs 141 e 160, a participação dos acionistas minoritários era registrada com base na proporção do capital, reservas e resultados dos acionistas ou sócios minoritários, e normalmente destacada em grupo isolado no balanço patrimonial consolidado, imediatamente antes do patrimônio líquido.

As US GAAP, através do SFAS 94, só permitem a consolidação se houver controle isolado sobre a sociedade investida, com participação da investidora de mais de $50 \%$ do capital votante. No SFAS 94, o FASB define que as subsidiárias sobre as quais a controladora detém controle temporário não devem ser consolidadas, bem como aquelas cujo controle não mais pertence a holding, em razão, por exemplo, de falência ou reorganização corporativa.

\begin{tabular}{|c|c|c|c|c|}
\hline $\begin{array}{c}\text { Participação } \\
\text { Societária no } \\
\text { Capital Votante }\end{array}$ & $\begin{array}{c}\text { Nível de } \\
\text { Influência } \\
\text { Econômica }\end{array}$ & $\begin{array}{c}\text { Tipo de } \\
\text { Investimento }\end{array}$ & $\begin{array}{c}\text { Método de } \\
\text { Avaliação }\end{array}$ & $\begin{array}{c}\text { Apresentação no } \\
\text { Balanço Patrimonial }\end{array}$ \\
\hline $0 \%-20 \%$ & $\begin{array}{c}\text { Nenhuma ou } \\
\text { Pequena Influência }\end{array}$ & $\begin{array}{c}\text { Temporário de Curto } \\
\text { ou Longo Prazo } \\
\text { (CP/LP) }\end{array}$ & $\begin{array}{c}\text { Fair Value ou Custo } \\
\text { (nesta ordem) }\end{array}$ & $\begin{array}{c}\text { Investimentos } \\
\text { (CP ou LP) }\end{array}$ \\
\hline $0 \%-20 \%$ & $\begin{array}{c}\text { Influência } \\
\text { Significativa }\end{array}$ & Investida & MEP & Investimentos \\
\hline $20 \%-50 \%$ & $\begin{array}{c}\text { Influência } \\
\text { Significativa }\end{array}$ & Investida & MEP & Investimentos \\
\hline Inferior a 50\% & $\begin{array}{c}\text { Controle em } \\
\text { conjunto }\end{array}$ & Investida & MEP & Investimentos \\
\hline $50 \%-100 \%$ & Controle & Subsidiária & Consolidação & $\begin{array}{c}\text { Demonstrações } \\
\text { Consolidadas }\end{array}$ \\
\hline
\end{tabular}

Quadro 3 - Investimentos em Participações Societárias com Direito a Voto - US GAAP

Fonte: elaborado pelos autores.

O ARB 51 orienta que todos os saldos e transações intragrupo, e também os lucros e prejuízos, sejam eliminados das demonstrações consolidadas. O SFAS 160 reiterou o posicionamento do ARB 51 para garantir que os fatos contábeis apresentados nas demonstrações correspondam a eventos reais que reflitam a posição financeira e o resultado do grupo. As empresas estrangeiras com ações negociadas nas bolsas norte-americanas precisam cumprir obrigações legais específicas que incluem o arquivamento anual do formulário 20-F, com informações sobre os resultados da empresa e seu desempenho. Outra diferença que poderia ser destacada é o prazo de defasagem permitido para que as DF sejam consolidadas no Brasil e nos EUA. Neste, as demonstrações das subsidiárias devem ser datadas de, no máximo, 90 dias antes do exercício contábil da controladora. Já naquele, mesmo com a atualização da Lei $n^{\circ}$. 6.404, o prazo máximo permitido é menor, de 60 dias.

Futura e Santos (2006) observaram que há diferenças na forma de reconhecimento e de apresentação nas DF consolidadas dos investimentos em joint ventures de acordo com o país onde referida consolidação é efetuada. Tais investimentos, caracterizados por serem controlados de forma conjunta, podem ser apresentados de maneira variada quanto às práticas de consolidação proporcional ou integral. Esta prática somente permite que se consolide os investimentos sob controle exclusivo da entidade. Os defensores daquela prática contábil, porém, argumentam que sua não utilização é um subterfúgio que as empresas utilizam para esconder as operações de crédito e financiamentos contratadas pelas joint ventures. Os resultados encontrados indicaram que há diferenças significativas entre os valores registrados 
no Passivo Circulante, Exigível de Longo Prazo e Capital de Terceiros sobre Capital Próprio, calculados com e sem as práticas da consolidação proporcional.

Algumas vezes pode haver a necessidade de ajustes para divulgação externa das DF consolidadas, elaboradas segundo as US GAAP, em relação as BR GAAP. As práticas contábeis brasileiras e norte-americanas para a consolidação das DF apresentam similaridades e divergências, que precisam ser conhecidas para que se possa analisar de forma adequada as informações financeiras. Uma das principais diferenças existente nas $\mathrm{CN}$ está relacionada com a evidenciação dos investimentos em subsidiárias controladas em conjunto, que no Brasil requerem consolidação proporcional e nos EUA são apenas registrados na conta Investimento, pelo MEP. Essas diferenças requerem atenção especial por parte dos profissionais de finanças, investidores e outros agentes do mercado que são usuários das informações constantes das DF. Uma análise sem considerar essas informações poderia promover margem para oportunismo e gerar custos adicionais de monitoramento por parte dos acionistas e distorcer a percepção dos usuários das informações contábeis, especialmente os investidores estrangeiros.

Em estudo recente, Miller, Bahnson e Mc Allister (2008) analisaram os impactos do SFAS 141, editado em dezembro de 2007, que trata de CN realizadas sob os US GAAP. Eles mencionam que este pronunciamento foi um trabalho conjunto do FASB (Financial Accounting Standards Board) com o IASB (International Accounting Standards Board) que buscou ajudar os usuários a tomarem melhores decisões relativas à contabilização das operações de F\&A. As combinações, do ponto de vista contábil, têm sido operações controversas desde há muito tempo pois não se sabe qual das diferentes visões sobre as $\mathrm{CN}$ poderia oferecer as informações mais úteis. Adicionalmente, muitos problemas surgem na implementação de questões únicas em determinados tipos de $\mathrm{CN}$, especialmente, no que se refere ao tratamento das participações minoritárias e do goodwill e outros ativos intangíveis. Os autores concluíram que o conceito mais importante tratado no Pronunciamento 141 do FASB se refere ao surgimento da entidade econômica pelo processo de consolidação, que deveria assumir $100 \%$ dos ativos da adquirida, obrigações correlatas e interesses dos minoritários.

Enquanto no Brasil se consideram os aspectos jurídicos e os impactos fiscais que derivam das transações de $\mathrm{CN}$, os US GAAP valorizam a essência, não importando a forma de obtenção do controle, mas sim sua mudança para a empresa investidora. Esse ponto não foi afetado pelos SFASs 141 e 160, porque em junho de 2001 o FASB já havia aprovado dois pronunciamentos que alteravam alguns itens relacionados às operações de $\mathrm{CN}$. Neles, eliminou-se o método pooling (combinação de interesses) e aplicou-se o método purchase (compras) para todas as operações CN. Além dessa alteração, esses dois pronunciamentos trouxeram também alterações em relação ao goodwill, que não mais seria amortizado.

No Brasil, as BR GAAP determinam que nas operações de incorporação, de fusão ou de cisão que forem realizadas entre partes não relacionadas e estiverem vinculadas à efetiva transferência de controle, todos os ativos e passivos deverão ser identificados, avaliados e contabilizados a valor de mercado (SCHIMIDT et al., 2005). O processo de mensuração do goodwill e sua amortização deveria ser feito de forma cautelosa para que a avaliação represente adequadamente o valor desse ativo intangível, por ser um processo bastante complexo. Tendo em vista que o valor do goodwill está intimamente ligado a outros intangíveis não identificáveis, observa-se que uma forma teoricamente aceitável de mensurar o valor total da empresa é aquela determinada subjetivamente pelos investidores. Segundo Quilligan (2006) esse é o goodwill adquirido, entendido como o excesso de preço pago pela compra de um empreendimento (ou participação). 


\section{APRESENTAÇÃO E ANÁLISE DO CASO}

O controle acionário de algumas empresas de geração e distribuição anteriormente de propriedade da Eletrobrás ou dos vários Estados foi vendido para investidores estrangeiros. Alguns governos estaduais também venderam sua participação em grandes empresas de distribuição no mesmo período (COPEL, 2008c). No entanto, o principal órgão regulador do setor, a Agência Nacional de Energia Elétrica (ANEEL), criada pela Lei n ${ }^{\circ} 9.427$, de 26 de dezembro 1996, estabeleceu limites para a concentração de serviços e atividades no âmbito do setor elétrico. Sob esses limites, com exceção das companhias participantes do Plano Nacional de Privatização, nenhuma companhia do setor elétrico e suas controladas poderia ultrapassar determinadas cotas do mercado de distribuição brasileiro (ANEEL, 2008).

A Eletrobrás e suas subsidiárias são responsáveis por aproximadamente $39,0 \%$ da capacidade de geração de energia do Brasil e por $60,6 \%$ da capacidade instalada de transmissão igual ou superior a $230 \mathrm{KV}$. Além disso, alguns Estados brasileiros controlam empresas envolvidas na geração, transmissão e distribuição de eletricidade, tais como a Companhia Energética de São Paulo (CESP), a Companhia Energética de Minas Gerais (CEMIG) e a COPEL, entre outras.

Atualmente, a COPEL atende diretamente a cerca de 3,5 milhões de unidades consumidoras em 393 municípios e 1.116 localidades (distritos, vilas e povoados). Nesse universo incluem-se 2,7 milhões de lares, 58 mil indústrias, 286 mil estabelecimentos comerciais e 333 mil propriedades rurais. Sua estrutura é composta de 8.300 colaboradores que cuidam da operação do parque gerador próprio composto por 18 usinas com potência instalada totaliza $4.550 \mathrm{M}$; do sistema de transmissão com $7.352 \mathrm{~km}$ de linhas e 133 subestações automatizadas, totalizando 16,7 mil MVA (megavolts-ampéres) de potência de transformação; do sistema de distribuição, com 171.524 km de linhas e 236 subestações; do sistema óptico de telecomunicações, com $5.054 \mathrm{~km}$ de cabos auto sustentados instalados no anel principal e radiais urbanos, alcançando 181 cidades do estado do Paraná (COPEL, 2008b,c).

As demonstrações contábeis consolidadas da COPEL foram apresentadas em conformidade com os BR GAAP - baseados na Lei $\mathrm{n}^{\circ}$. 6.404/76, com as alterações introduzidas pelas Leis $n^{\circ}$. 9.457/97 e 10.303/01 - e com a Instrução CVM nº. 247/1996 e deliberações posteriores, além de regulamentações específicas do setor. As DF consolidadas contemplam a controladora, as subsidiárias integrais $\mathrm{e}$ as sociedades controladas indiretamente. $\mathrm{Na}$ consolidação, foram eliminados os investimentos da companhia com o patrimônio líquido das controladas, bem como os saldos de ativos, passivos, receitas, custos e despesas decorrentes de operações entre as companhias, tendo sido destacada a participação dos acionistas minoritários, de forma que as demonstrações contábeis consolidadas representem efetivamente os saldos de transações com terceiros.

Tendo em vista as diferenças entre os BR GAAP e US GAAP, percebeu-se que o lucro líquido sob os BR GAAP foi de $\mathrm{R} \$ 1.242,7$ milhões em 2006, $\mathrm{R} \$ 502,4$ milhões em 2005 e $\mathrm{R} \$ 369,6$ milhões em 2004. Sob os US GAAP, ter-se-ia registrado lucro líquido de R $\$ 1.019,0$ milhões em 2006, R \$ 556,5 milhões em 2005 e R $\$ 124,1$ milhões em 2004. O patrimônio líquido sob os BR GAAP era de R\$ 6.376,3 milhões em 31 de dezembro de 2006 e R\$ 5.487,2 milhões em 31 de dezembro de 2005. Sob US GAAP, ter-se-ia registrado patrimônio líquido de $\mathrm{R} \$ 7.181,5$ milhões em 31 de dezembro de 2006 e $\mathrm{R} \$ 5.964,0$ milhões em 31 de dezembro de 2005. Observou-se que a COPEL adotou a SFAS 158 para as DF a partir de 31 de dezembro de 2006.

A participação nos Resultados de Coligadas resultou em prejuízo de $\mathrm{R}$ \$ 6,2 milhões em 2006 e em lucro de $\mathrm{R} \$ 9,0$ milhões em 2005. O prejuízo em 2006 foi resultado principalmente da contabilização de prejuízo com as coligadas Sercomtel Telecomunicações de R \$ 11,7 milhões e Sercomtel Celular de R\$ 2,7 milhões. As participações societárias da 
COPEL em subsidiárias coligadas e controladas podem ser visualizadas no Quadro 4, segundo os BR GAAP e US GAAP.

\begin{tabular}{|c|c|c|c|c|}
\hline Empresa & $\begin{array}{c}\text { Participação } \\
\text { societária } \\
(\%)\end{array}$ & $\begin{array}{l}\text { Relação de } \\
\text { controle }\end{array}$ & \begin{tabular}{|l|} 
Apresentação \\
em US GAAP
\end{tabular} & $\begin{array}{l}\text { Apresentação } \\
\text { em BR GAAP }\end{array}$ \\
\hline $\begin{array}{l}\text { Braspower International Engineering S/C } \\
\text { Ltda. }\end{array}$ & 49 & Coligada & MEP & MEP \\
\hline Carbocampel S.A. & 49 & Subsidiária & MEP & MEP \\
\hline $\begin{array}{l}\text { Centrais Elétricas do Rio Jordão S.A. - } \\
\text { ELEJOR }\end{array}$ & 70 & Controlada & Consolidação & Consolidação \\
\hline Centrais Eólicas do Paraná Ltda. & 30 & Coligada & MEP & MEP \\
\hline $\begin{array}{l}\text { Companhia Paranaense de Gás - } \\
\text { COMPAGAS }\end{array}$ & 51 & Controlada & Consolidação & Consolidação \\
\hline COPEL Distribuição S.A. & 100 & Subsidiária Integral & Consolidação & Consolidação \\
\hline COPEL Empreendimentos Ltda & 60 & Controlada & Consolidação & Consolidação \\
\hline COPEL Geração S.A. & 100 & Subsidiária Integral & Consolidação & Consolidação \\
\hline COPEL Participações S.A & 100 & Subsidiária Integral & Consolidação & Consolidação \\
\hline COPEL Telecomunicações S.A. & 100 & Subsidiária Integral & Consolidação & Consolidação \\
\hline COPEL Transmissão S.A. & 100 & Subsidiária Integral & Consolidação & Consolidação \\
\hline \multicolumn{5}{|l|}{ COPEL-Amec S/C } \\
\hline Ex-COPEL-Agra S/C Ltda & 48 & $\begin{array}{l}\text { Em fase de } \\
\text { liquidação }\end{array}$ & MEP & MEP \\
\hline Dominó Holdings S.A. & 15 & Coligada & Custo & MEP \\
\hline ESCO Electric Ltda. & 40 & Coligada & MEP & MEP \\
\hline Sercomtel Celular S.A. & 45 & Coligada & MEP & MEP \\
\hline Sercomtel Telecomunicações S.A. & 45 & Coligada & MEP & MEP \\
\hline UEG Araucária Ltda & 60 & Controlada & Consolidação & Consolidação \\
\hline $\begin{array}{l}\text { Usina Hidrelétrica Dona Francisca } \\
\text { Energética S.A. }\end{array}$ & 23,03 & Coligada & MEP & MEP \\
\hline $\begin{array}{l}\text { Usina Hidrelétrica Foz do Chopin Energética } \\
\text { Ltda. }\end{array}$ & 35,77 & Coligada & MEP & MEP \\
\hline Usina Termelétrica Araucária & 80 & Controlada & Consolidação & Consolidação \\
\hline Ecoeletric Ltda & 40 & Coligada & MEP & MEP \\
\hline
\end{tabular}

Quadro 4 - Investimentos da COPEL em subsidiárias coligadas e controladas em US GAAP e BRGAAP

Fonte: elaborado pelos autores baseado no relatório 20 - F (SEC, 2008; COPEL 2008a, b)

Antes de analisar as informações do Quadro 3, vale dizer que foram constatadas duas inconsistências entre as informações em BR GAAP, observadas nas notas explicativas às DF de dezembro de 2006 (COPEL, 2008a) e em US GAAP (SEC, 2008; COPEL, 2008b). Tais inconsistências são relativas à participação total na UEG Araucária, apresentada em BR GAAP em 80\%, e na COPEL Empreendimentos, apresentada em 100\% do capital.

As diferenças entre a normatização do Brasil e dos Estados Unidos que provocam os efeitos mais significativos sobre o lucro líquido e o patrimônio líquido são o tratamento de juros capitalizados, as normas sobre indexação do ativo imobilizado, o tratamento de obrigações especiais, o tratamento de ativos regulamentares diferidos e o tratamento de benefícios futuros de assistência à saúde e aposentadoria. Adicionalmente, observaram-se divergências no processo de consolidação das demonstrações contábeis frutos de aquisições de negócios ou participações acionárias (COPEL, 2008b).

Alguns exemplos que afetaram o processo de consolidação das DF são a aquisição, em 1998, de 45\% das ações da Sercomtel S.A. - Telecomunicações e de $45 \%$ das ações da Sercomtel Celular S.A., ambas empresas públicas de telecomunicações do Estado do Paraná. O valor total pago pelas duas empresas foi de $\mathrm{R} \$ 186.000$, resultando em ágio de $\mathrm{R} \$ 48.103$. 
Em 2003, a Companhia firmou contrato com a Triunfo Participações e Investimentos S.A. para adquirir 30\% das ações ordinárias da ELEJOR. Em 2004, a COPEL adquiriu mais 30\% de suas ações ordinárias, passando a deter 70\% do controle acionário da ELEJOR. Em 2006, a COPEL Participações, por meio de sua controlada COPEL Empreendimentos Ltda., adquiriu $60 \%$ do capital social da UEG Araucária Ltda., no montante de $\mathrm{R} \$ 436.563$, equivalente a US\$ 190 milhões.

Para apresentação no Brasil, a COPEL vem contabilizando o resultado da avaliação dos investimentos pelo MEP, limitado ao valor de sua participação no investimento (COPEL, 2008a). Nos EUA, entretanto, só os investimentos em coligadas estão registrados pelo MEP, sendo os outros investimentos registrados ao custo, subtraídos pelas provisões para perdas (COPEL, 2008b). Um exemplo disso, foi o investimento na Dominó Holdings S.A., que no Brasil, atendendo aos BR GAAP, foi avaliado pelo MEP. No relatório 20-F, entretanto, percebeu-se que ele teve de ser reclassificado para atender às exigências dos US GAAP.

As diferenças no processo de consolidação são frutos da forma de avaliação das participações nos resultados de coligadas no Brasil e nos EUA, antes do advento da Lei nº. 11.638 de 2007. De acordo com os BR GAAP, o MEP era aplicado para investimentos em que o investidor tinha influência e/ou participação de pelo menos $20 \%$, bem como para investimentos considerados relevantes, incluindo participações entre $10 \%$ e $19 \%$ que representem mais de $10 \%$ individualmente ou $15 \%$ de forma agregada em relação ao patrimônio líquido do investidor. Nos EUA, de acordo com os US GAAP, o MEP somente é exigido para investimentos com influência significativa em investimentos com participação abaixo de $20 \%$ e quando a participação for superior a 20\%, conforme estabelecido no APB 18 - que trata do método da equivalência para contabilidade de investimentos em ações ordinárias. Nesse sentido, o investimento na Dominó Holdings S.A. (participação de 15\%) deveria ter sido contabilizada pelo método de custo.

A COPEL não possuía influência significativa sob esse investimento. Assim, para fins de reconciliação com os US GAAP, os resultados de equivalência patrimonial da Dominó Holdings S.A. foram revertidos (COPEL, 2008b). A companhia recebeu dividendos da Dominó Holdings S.A. no valor de R\$2.010 em 2006 ( R \$ 2.175 em 2005 e R\$2.018 em 2004). De acordo com os US GAAP, encargos diferidos em afiliadas deveriam ser apropriados conforme incorridos e os ajustes registrados nos resultados de equivalência patrimonial das coligadas. Além disso, de acordo com as normas de contabilidade específicas do setor de energia brasileiro, o resultado da participação em coligadas é reconhecido em uma conta especial na demonstração do resultado antes da conta de outras receitas (e despesas). De acordo com os US GAAP, porém, o resultado da participação em coligadas é classificado na demonstração do resultado antes do imposto de renda.

$\mathrm{Na}$ análise, percebeu-se uma divergência na operação de aquisição de $30 \%$ das ações ordinárias da ELEJOR. Nessa operação, a COPEL passou a deter 70\% do controle acionário da ELEJOR e 35\% do total de ações da empresa. Sob os US GAAP, a empresa registrou essa aquisição com base no valor justo dos ativos adquiridos e dos passivos assumidos de acordo com o método de compra previsto na SFAS 141. Segundo os BR GAAP, porém, a avaliação é feita com base no valor de mercado dos ativos líquidos da adquirida.

$\mathrm{Na}$ transação de aquisição das ações preferenciais subscritas pela ELETROBRÁS, verificaram-se diferenças no tratamento entre as normas dos dois países. Tal transação foi feita em 32 parcelas trimestrais, ajustadas pelo IGP-M, acrescidas de juros de $12 \%$ ao ano e deduzidas dos dividendos pagos, com início em 24 meses após o início das operações da ELEJOR. Analisando a aquisição, constatou-se que, de acordo com os BR GAAP, os juros e a variação monetária no valor de $\mathrm{R} \$ 49.352$ foram registrados em empréstimos e financiamentos de longo prazo em 31 de dezembro de 2006. A consolidação as ações preferenciais da ELEJOR em posse da ELETROBRÁS foram registradas como participação 
minoritária no valor de $\mathrm{R} \$ 64.477$ e $\mathrm{R} \$ 65.134$ em 31 de dezembro de 2006 e 2005, respectivamente. De acordo com os US GAAP, porém, conforme exigido pela SFAS 150, "Contabilidade de Determinados Instrumentos Financeiros com Características de Passivos e Patrimônio", as ações resgatáveis da ELEJOR em posse da ELETROBRÁS foram registradas no exigível a longo prazo em 31 de dezembro de 2006.

A aquisição da COPEL Empreendimentos Ltda. - antiga El Paso Empreendimentos e Participações Ltda. - foi registrada, sob os US GAAP nos EUA, com base no valor justo dos ativos adquiridos e dos passivos assumidos de acordo com o método de compra previsto na SFAS 141, diferentemente do que preconiza os BR GAAP que focam no valor de custo ou de mercado, dos dois o menor.

O processo de consolidação também produziu diferenças na conversão dos valores dos DF do Brasil para os EUA. Assim, observou-se na análise dos demonstrativos constantes nos quadros das páginas F-93 e F-94, do formulário 20-F (SEC, 2008) que a consolidação provocou diferenças no balanço patrimonial e no patrimônio líquido da COPEL. Dessa análise, percebeu-se que a reversão de participação no resultado de coligadas - reconhecida pelos BR GAAP - gerou um acréscimo de $\mathrm{R} \$ 3,088$ milhões; que a reversão do contrato de concessão da ELEJOR - sob os BR GAAP - produziu um acréscimo de R \$ 32,170 milhões; e que amortização de ágio alocado à concessão da UEG Araucária - reconhecido sob os US GAAP nos EUA - provocou um estorno de R\$ 1,979 milhão (quadro da pág. F-94, COPEL, 2008b).

Os efeitos dessas transações na reconciliação dos resultados entre BR GAAP e US GGAP sob o patrimônio líquido são que a reversão de participação no resultado de coligadas - reconhecida pelos BR GAAP - produziu um estorno de R\$ 52,22 milhões; que a reversão do contrato de concessão da ELEJOR - reconhecido sob os BR GAAP - gerou um saldo de R\$ 32,17 milhões; e que a amortização de ágio alocado à concessão da UEG Araucária reconhecido sob os US GAAP nos EUA - provocou uma reversão de R \$ 1,979 milhão (quadro da pág. F-93, COPEL, 2008b). Finalmente, observou-se que de um modo geral, os BR GAAP exigem que menos informações sejam divulgadas nas notas explicativas das DF do que os US GAAP.

\section{CONCLUSÕES}

A GC é um tema que tem tido notável destaque, tanto no meio acadêmico quanto no meio empresarial, por buscar reduzir ao máximo o conflito de agência entre os proprietários e gerentes, por tentar otimizar o desempenho de uma companhia ao proteger todas as partes interessadas, por facilitar o acesso às fontes de capital e, ainda, por aumentar o valor da sociedade e contribuir para sua perenidade. A transparência é um dos determinantes da boa GC que busca que haja um nível adequado de evidenciação contábil para promover maior clareza na divulgação das informações financeiras além das fronteiras, para salvaguardar o interesse dos investidores e para reduzir a assimetria informacional entre proprietários e gestores. Uma maior evidenciação poderia reduzir os custos de capital, frutos das atividades de monitoramento, facilitar o processo de tomada de decisões e melhorar o nível de governança das empresas.

O objetivo deste estudo foi analisar a necessidade de ajustes para divulgação externa das DF consolidadas, em CN, de uma empresa que divulga suas informações no Brasil e nos EUA. Além de discutir por que eles ocorrem, como são evidenciados nas DF e de que modo divergências informacionais advindas de diferenças nas práticas de consolidação afetam os investidores e as boas práticas de GC. Baseada na Teoria de Finanças, a pesquisa descrita neste artigo teve como foco promover melhorias em aspectos da GC pela redução da assimetria informacional dos investidores. Observou-se a necessidade de ajustes para 
divulgação externa das demonstrações financeiras consolidadas da COPEL na divulgação de suas informações nos EUA, em relação ao que fora evidenciado no Brasil.

Os resultados encontrados confirmaram vários pontos da análise teórica preliminar que foi feita comparando-se a legislação e estudos sobre o tema no Brasil e nos EUA. Percebeu-se que a prestação de contas e que a divulgação financeira de empresas com ações negociadas em bolsas de diferentes países devem ser realizadas em sintonia com as diferentes legislações. As empresas estrangeiras com ações negociadas nas bolsas norte-americanas, por exemplo, precisam cumprir obrigações legais específicas que incluem o arquivamento anual do formulário 20-F, com informações sobre os resultados da empresa, seu desempenho, perspectivas e corpo diretivo; sobre honorários e serviços prestados para a companhia; e sobre códigos de ética e sistemas de controle internos adotados para melhorar os níveis de GC.

As operações de CN são uma opção estratégica que tem se intensificado, mas que carecem de divulgar informações adicionais para melhorar seu nível de GC. Do ponto de vista contábil, elas têm sido operações com problemas no que se refere ao tratamento das participações minoritárias e do goodwill e outros ativos intangíveis. Da análise teórica percebeu-se que, as participações em que a investidora exerce controle em conjunto são tratadas diferentemente pelos BR GAAP e US GAAP.

No Brasil, a empresa estudada vem contabilizando o resultado da avaliação dos investimentos pelo MEP. Nos EUA, entretanto, os investimentos em coligadas estão registrados pelo MEP e os outros investimentos, registrados pelo método de custo. Observaram-se diferenças no lucro líquido e PL divulgado sob os BR GAAP e US GAAP. As diferenças que provocam os efeitos mais significativos sobre o lucro líquido e o PL são o tratamento de juros capitalizados, as normas sobre indexação do ativo imobilizado, o tratamento de obrigações especiais, o tratamento de ativos regulamentares diferidos e o tratamento de benefícios futuros de assistência e divergências no processo de consolidação, frutos de aquisições de negócios ou participações acionárias. Constatou-se também que enquanto no Brasil, o prazo de defasagem permitido para que as DFS sejam consolidadas é de 60 dias, nos EUA, o prazo é de 90 dias.

As diferenças no processo de consolidação são frutos da forma de avaliação das participações nos resultados de coligadas no Brasil e nos EUA. Nesse sentido, houve investimentos contabilizados pelo MEP, no Brasil, sobre os quais a companhia não possuía influência significativa que, para fins de reconciliação com os US GAAP, tiveram que ser revertidos para o método de custo. Analisando as normas de contabilidade específicas do setor de energia brasileiro, percebeu-se que o resultado da participação em coligadas é reconhecido em uma conta especial na demonstração do resultado antes da conta de outras receitas (despesas). De acordo com os US GAAP, porém, o resultado da participação em coligadas é classificado na demonstração do resultado antes do imposto de renda.

$\mathrm{Na}$ aquisição de participações acionárias, sob os US GAAP, a COPEL registrou a aquisição de ações ordinárias com base no valor justo dos ativos adquiridos e dos passivos assumidos de acordo com o método de compra. Segundo os BR GAAP, a avaliação foi feita com base no valor de mercado dos ativos líquidos da adquirida. Na aquisição de ações preferenciais, de acordo com os BR GAAP, os juros e a variação foram registrados em empréstimos e financiamentos de longo prazo e a consolidação das ações preferenciais foram registradas como participação minoritária. De acordo com os US GAAP, porém, as ações resgatáveis devem ser registradas no exigível a longo prazo.

Ressalta-se que o estudo das diferenças e dos meios de minimizá-las é um dos maiores desafios do processo de harmonização das normas contábeis, especialmente das consolidações das DF em CN. Tal desafio sugere a recomendação de novos estudos para aprofundar no conhecimento das diferenças nas normas relacionadas ao registro dos fatos contábeis e à divulgação financeira entre os países, para facilitar a comparabilidade entre as informações 
neles divulgadas e para ajudar no processo de harmonização internacional. Ademais esses estudos colaborariam para atingir o objetivo fundamental da contabilidade, de prestar informações úteis, relevantes e confiáveis para a tomada de decisões.

Em síntese, nesta pesquisa, verificou-se que (1) há significativas divergências nas informações consolidadas, em função das diferentes práticas do Brasil e dos EUA, para grupos com investimentos em CN; que (2) o processo de consolidação das DF é vital na análise financeira das $\mathrm{CN}$; que (3) a compreensão das singularidades do tratamento das $\mathrm{CN}$ nos dois países pode reduzir os custos de agência e melhorar o nível de GC; e que (4) o desconhecimento dessas diferenças pode prejudicar a análise financeira e, consequentemente, as decisões de investimento nas empresas dos grupos que realizam $\mathrm{CN}$.

\section{REFERÊNCIAS}

AGÊNCIA NACIONAL DE ENERGIA ELÉTRICA (ANEEL). Regulamentação. Disponível em: www.aneel.gov.br . Acesso em: 15 jun. 2008.

AMERICAN INSTITUTE OF CERTIFIED PUBLIC ACCOUNTANTS (AICPA). AU Section 411 - The meaning of present fairly in conformity with generally accepted accounting principles. In: Auditing and Accounting Guides, Set., 2008.

AMARAL, H. F.; IQUIAPAZA, R. A.; TOMAZ, W. P; BERTUCCI, L. A. Corporate governance and release of annual financial statements. Contabilidade Vista \& Revista, v. 19, n. 1, p. 61-82, jan./mar., 2008.

BOLSA DE VAlORES DE SÃO PAUlO (BOVESPA). Companhias listadas - COPEL. Disponível em: www.bovespa.com.br. Acesso em: 05 maio 2008.

BOLSA DE VALORES DE SÃO PAULO (BOVESPA). Níveis de governança corporativa. Disponível em: www.bovespa.com.br. Acesso em: 10 jul. 2008.

BRASIL. Lei $\mathbf{n}^{\mathbf{0}} \mathbf{. 1 0 . 3 0 3}$, de 31 de outubro de 2001. Altera e acrescenta dispositivos na da Lei $\mathrm{n}^{\mathrm{o}} .6 .404$ de 1976.

BRASIL. Lei $\mathbf{n}^{\mathbf{0}}$ 11.638, de 28 de dezembro de 2007. Altera e revoga dispositivos da Lei $\mathrm{n}^{\circ}$ 6.404 e da Lei $\mathrm{n}^{\circ} 6.385$ e estende às sociedades de grande porte disposições relativas à elaboração e divulgação de demonstrações financeiras.

BRASIL. Lei no 6.404, de 15 de dezembro de 1976. Dispõe sobre as Sociedades por Ações.

BRASIL. Lei $\mathbf{n}^{\mathbf{0}}$ 9.427, de 26 de dezembro 1996. Institui a Agência Nacional de Energia Elétrica (ANEEL), disciplina o regime das concessões de serviços públicos de energia elétrica, e dá outras providências.

BRASIL. Lei n⿳0 9.457, de 5 de maio de 1997. Altera dispositivos da Lei nº. 6.404 de 1976.

CASTRO, J. M. Métodos e técnicas de pesquisa. Manual prático. Belo Horizonte: Mestrado em Administração - MPA PUC-Minas e Fundação Dom Cabral, 2002.

COMISSÃO DE VALORES MOBILIÁRIOS (CVM). Instrução CVM no 247, de 27 de março de 1996. Dispõe sobre a avaliação de investimentos em sociedades coligadas e controladas e sobre os procedimentos para elaboração e divulgação das demonstrações contábeis consolidadas.

COMISSÃO DE VALORES MOBILIÁRIOS (CVM). Recomendações da CVM sobre governança corporativa. 2002. Acesso em: 19 jul. 2008.

COMISSÃO DE VALORES MOBILIÁRIOS (CVM). Deliberação no $\mathbf{~ 4 8 8}^{\mathbf{4}}$, de 06 de outubro de 2005. Aprova o Pronunciamento do IBRACON NPC $\mathrm{n}^{\circ} .27$ sobre Demonstrações 
IMPACTOS DA GOVERNANÇA CORPORATIVA E DA ESTRUTURA DE CONTROLE NA 97 CONSOLIDAÇÃO DE DEMONSTRAÇÕES FINANCEIRAS EM COMBINAÇÕES DE NEGÓCIOS: O ESTUDO DE CASO DA COPEL

Contábeis - Apresentação e Divulgação. Disponível em: <http://www.cvm.gov.br>. Acesso em: 19 jul. 2008.

COMPANHIA PARANAENSE DE ENERGIA ELÉTRICA (COPEL). Relatório Anual 2006. Belo Horizonte, 2008a. Disponível em: <www.bovespa.com.br〉. Acesso em: 04 maio 2008.

COMPANHIA PARANAENSE DE ENERGIA ELÉTRICA (COPEL). Demontrativos Financeiros 2006. Belo Horizonte, 2008b. Disponível em: <www.bovespa.com.br>. Acessado em 04 de maio de 2008.

COMPANHIA PARANAENSE DE ENERGIA ELÉTRICA (COPEL). Formulário 20-F 2006. 2008c. Disponível em: <www.nyse.com>. Acesso em: 04 maio 2008.

DAVIS, MICHAEL; LARGAY III, JAMES A. Consolidated Financial Statements. The CPA Journal, p. 26-31, Feb./2008.

EL HAJJ, Z. S.; LISBOA, L. P. Business combinations e consolidação das demonstrações contábeis. Revista Contabilidade \& Finanças, v. 16, n. 27, p. 33-58, 2001.

EPSTEIN, B. J.; NACH, R.; BRAGG, S. Willey GAAP 2006. Hoboken: Wiley, 2005.

FINANCIAL ACCOUNTING STANDARDS BOARD (FASB). SFAS 160 - Noncontrolling Interests in Consolidated Financial Statements. Emitido em dezembro de 2007.

FINANCIAL ACCOUNTING STANDARDS BOARD (FASB). SFAS 94 - Consolidation of All Majority_Owned Subsidiaries. Emitido em outubro de 1987.

FINANCIAL ACCOUNTING STANDARDS BOARD (FASB). SFAC 1 - Objectives of Financial Reporting by Business Enterprises. Emitido em novembro de 1978

FINANCIAL ACCOUNTING STANDARDS BOARD (FASB). SFAS 141 - Business Combinations. Emitido em 30 de junho de 2001.

FUTURA, F.; SANTOS, A. As exigibilidades nas demonstrações contábeis consolidadas de empresas com investimentos em joint ventures. In: ENANPAD, 30., 2006, Salvador/BA. Anais ... Rio de Janeiro: ANPAD, 2006.

INSTITUTO BRASILEIRO DE CONTADORES. Pronunciamento NPC 27. Dispõe sobre demonstrações contábeis - apresentação e divulgação. Disponível em: <http://www.relt.com.br/ibracon/>. Acesso em: 10 jul. 2008.

INSTITUTO BRASILEIRO DE GOVERNANÇA CORPORATIVA (IBGC). Governança corporativa. 2008. Disponível em: <www.ibgc.org.br>. Acesso em: 10 jul. 2008.

JENSEN, M. C.; MECKLING, W. H. Theory of the firm: managerial behavior, agency, costs and ownership structure. Journal of Financial Economics, v. 3, p. 305, Oct., 1976.

JORDÃO, R. V. D.; SOUZA, A. A. de. Uma discussão sobre o papel da ética de resultados nos principais modelos internacionais de controle interno. In: Congresso Nacional de Excelência em Gestão - Latec, 4., 2008, Niterói. Anais... Niterói, 2008.

LANZANA, A. P.; SILVEIRA, A. M.; FAMÁ, R. Existe relação entre disclosure e governança corporativa no Brasil? In: ENANPAD, 30., 2006, Salvador/BA. Anais... Rio de Janeiro: ANPAD, 2006.

LEMES, S. L.; CARVALHO N. G.; OLIVEIRA-LOPES L. C. Comparabilidade entre os BR GAAP e os US GAAP: algumas evidências das companhias brasileiras listadas na NYSE. In: ENANPAD, 2007, Rio de Janeiro. Anais ... Rio de Janeiro: ANPAD 2007. 
MARTINS, V. A.; SILVA, R. L. M.; NARDI, P. C. C.. Governança corporativa e liquidez das ações. In: In: ENANPAD, 30., 2006, Salvador/BA. Anais... Rio de Janeiro: ANPAD, 2006.

MILLER, P. B. W.; BAHNSON, P. R.; Mc ALLISTER, B. P. A new day for business combinations. Journal of Accountancy, Jun. 2008.

QUILLIGAN, L. Intangible Assets identification and valuation under IFRS 3. Accountancy Ireland, v. 38, p. 10-12, Jun. 2006.

RICHARDSON, Roberto Jarry. Pesquisa social: métodos e técnicas. São Paulo: Atlas, 1999.

SANTOS, J. L.; SCHMIDT, P.; FERNANDES, L. A. Contabilidade avançada. São Paulo: Atlas, 2003.

SCHIMIDT, P.; SANTOS, J. L.; GOMES, J. M. M.; FERNANDES, L. A.; PINHEIRO, P. R.; MACHADO, N. P. Evidenciação de ativos intangíveis: uma forma de minimizar os problemas causados pela seleção adversa. In: ENANPAD, 29., 2005, Brasília. Anais... Rio de Janeiro: ANPAD, 2007.

SHORTRIDGE, R. T; SMITH, P. Understanding consolidation. The CPA Journal. v. 77, n. 4, p. 22-26, Apr. 2007.

STICKNEY, C.; WEIL, R. Contabilidade financeira. São Paulo: Atlas, 2001.

YOUNG, D.; GUENTHER, D. A. Financial reporting environments and international capital mobility. Journal of Accounting Research, Chicago, v. 41, n. 3, p. 553-579, Jun. 2003. Disponível em: www.periodicos.capes.gov.br. Acesso em 14 de março de 2008. http://dx.doi.org/10.1111/1475-679X.00116 